\title{
A Community Capacity-Enhancement Approach to Breast and Cervical Cancer Screening among Older Women of Color
}

\author{
Karen Bullock and Sarah A. McGraw
}

In the Screening Older Minority Women project, the authors applied a community capacity-enhancement approach to promoting breast and cervical cancer screening among older women of color. Members of informal support networks were recruited for this health promotion intervention to empower Latina and African American women to engage in positive health behaviors. The authors describe the phases of the intervention and

the experiences from the community. Guidelines are identified to help researchers and practitioners in planning and implementing community health promotion intervention with women of color.

KEY WORDS: African American women; cancer screening; Latina women; mammography; older women

$\mathrm{B}$ y 2010, Americans can expect to see changes in community life that are the direct result of negative health status, especially for older people of color (U.S. Department of Health and Human Services, 2000). Although many health behaviors are widely practiced by older adults, people of color report apprehension about using health and medical services (Adams, 1995; Gamble, 1993; Han, Wells, \& Primas, 2003; Sullivan et al., 2001). Social workers interested in health promotion should be particularly concerned about this population because trends in cancer mortality over the past two decades show higher rates among women of color than white, non-Hispanic women (Marbella \& Layde, 2001; National Center for Health Statistics, 2001;Skinner,Arfken, \& Waterman, 2000). Breast cancer is the most common type of cancer in African American women (American Cancer Society, 2001), and cervical cancer, although readily curable if diagnosed and treated early, has remained a noted health problem for this group since the mid-1970s (Ries, Hankey, \& Edwards, 1990). Latinos have health profiles similar to those of African Americans (Markides, Rudkin, Angel, \& Espino, 1997; Selvin \& Brett, 2003), with Latina women being disproportionately affected by cancer-related illnesses (Cardin, Grimes, Jiang, Harrell,
\& Cano, 2001; Ramirez et al., 2000; Zambrana \& Ellis, 1995). Underutilization of Papanicolaou (Pap) smears and clinical breast exams put women of color at risk of cancer morbidity and mortality.

This article describes the processes of assessment, engagement, implementation, and evaluation of a research strategy used to enhance the capacity for health behavior change among older women of color. Discussion of experiences from the community and lessons learned provide insight and guidance for effective health promotion research.

\section{LITERATURE REVIEW}

\section{Community Capacity Enhancement}

Traditionally, communities of color have been considered "hard to reach" for inclusion in health behavior change strategies (Black, Stein, LovelandCherry, 2001; Braithwite \& Lythcott, 1989), and efforts to address population-specific needs have suffered from the lack of comprehensive planning and relied mostly on a deficit model to inform research and practice (Chaskin, Joseph, \& ChipendaDansokho, 1997; Morrison et al., 1997). The success of intervention strategies designed to bring about change in these populations depends on public engagement and community partnerships in both research and practice (Delgado, 2000; 
Ramirez-Valles, 2001). Although social work literature has documented the usefulness of informal networks (Hurdle, 2001) and community partnerships (Lesser, 2000) in reducing mortality rates and increasing the use of health practices, the enhancement of a community's capacity to facilitate the intervention has not been clearly delineated.

A community capacity-enhancement approach enables social workers to renew a long-standing tradition of collaboration between professionals and community members, resulting in an empowerment model for strengthening community resources. This is important in the effectiveness of health programs because the sustainability of an intervention depends on the capacity of the residents to bring about the necessary changes (Sellers, Crawford, Bullock, \& McKinlay, 1997). Furthermore, interventions are most effective when participants and facilitators are of a shared culture and there is a level of comfort in expressing concerns among themselves (Levy, 1985; Yancey \& Walden, 1994). We recognized that tailoring health promotion to the needs, beliefs, and cultural attitudes of women of color hinged on culturally congruent networks (Altpeter, Earp, \& Schopler, 1998; Bullock, 2004; Suarez, 1994).

Delgado (2000) described the community capacity-enhancement framework as a partnership in which knowledge and expertise of all collaborators are considered complementary, where increased skills and capacity at the community level can enhance utilization of the intervention. Implicit in this description is the objective to empower community members and reduce authority differentials between researchers and the target population. Enhancement of resources and capacity within communities of color may provide a means for ongoing sustainability even after the research project has ended.

The present research sought to promote cancer screening examinations among older women of color. Although we did not apply all the principles of the community capacity-enhancement framework, adhering to the specific processes of assessment, engagement, implementation, and evaluation helped to enhance resources, identify change in individual capacity, and improve attitudes and behavior toward health behaviors.

\section{HEALTH PROMOTION PROJECT}

The Screening Older Minority Women (SOMW) was a three-year project, designed to promote pub- lic health through breast and cervical exams and enhance the capacity of members of the community to influence health outcomes among African American and Latina women age 50 and older.The primary goal was to increase use of cancer screening tests, such as breast and cervical exams, Pap tests, and mammograms among these women. The behavior change intervention was adapted to engage social networks and community connections. Because we know that older women of color tend to use fewer cancer screening services (Clayton \& Byrd, 1993; Rimer, 1994), are more likely to rely on members of informal networks for social support (Bullock, 2004), and are less likely than other women to participate in research (Allen, 1994; Tessaro, Eng, \& Smith, 1993), it was important to go into the community for guidance in planning and implementing the intervention rather than rely on traditional models of health promotion that have tended to exclude elderly women of color (Levkoff \& Sanchez, 2003).

\section{Setting and Context}

The study took place in African American and Latino neighborhoods of two northeastern cities, Waterbury, Connecticut, and Boston, Massachusetts. These areas were selected because they had a high proportion of women of color and were similar in demographic and socioeconomic makeup. Both cities contained a health service that offered free or low-cost mammograms, as well as breast exams and Pap tests funded through each state by the Centers for Disease Control and Prevention [CDC] Breast and Cervical Cancer Early Detection Program. These two communities were targeted for intervention in an effort to increase early detection, which could be improved substantially through mammography and Pap tests (Lerman et al., 1994; Rimer, 1994). Conducting the research in cities where there was sufficient access to cancer prevention services was imperative.

\section{ASSESSMENT}

To take into account local values, history, culture, and expectations (Shavers-Hornaday, Lynch, Burmeister, \& Torner, 1997; Zambrana \& Ellis, 1995), an assessment of and validation by the local citizenry (that is, agencies, organizations, residents) was important. Community members' input greatly influenced the success of the SOMW project. 


\section{Community Advisory}

A local professional advisory group consisting of health professionals and community agency representatives was organized. This group offered guidance to the research team throughout the project by identifying issues that affect the health of community members, proposing solutions based on their perspectives as professionals of the community, and providing advice on how to engage older women of color in the SOMW health promotion project. Focus groups were convened at a local church to facilitate discussion among the SOMW research team from the New England Research Institutes, community-dwelling women, and the advisory group. The discussion included the purpose of the study, the recruitment process, and the hiring of community outreach workers to help facilitate the health promotion intervention. Information gathered during the meetings became a part of the assessment for building a collaborative partnership. Financial resources were allocated to the agencies, and a contractual agreement was made regarding the hiring of staff, workspace, and research protocol. Our collaborative goals were to improve health outcomes for communities of color and to do so in a culturally informed manner.

\section{ENGAGEMENT}

Engagement refers to the process of developing relationships, eliciting commitments from community residents, and helping ensure understanding and agreement between all significant parties (Poole, 1997). According to the principles of community capacity enhancement, the development of a "sense of belonging" and "connectedness" to the project is a critical dimension of community intervention (Delgado, 2000).

\section{Hiring Community Outreach Workers Coworkers}

During the engagement phase, women from local African American and Latino communities in Waterbury and Boston were employed as community outreach workers to facilitate the SOMW health promotion intervention. Two health care facilities agreed to collaborate on the project: Saint Mary's Hospital, in central Connecticut, which had a population of 500,000 for its catchment area, and Dimock Community Health Center in Boston, which had a population of 600,000 for its catchment area. Both community health in- stitutions also offer cancer detection and prevention services.

\section{Training the Coworkers}

The coworkers received didactic material on health behavior theories; cancer facts, including incidence and mortality rates; interviewing skills; recruitment competencies; and information about administrative procedures for data collection quality and accuracy. These women initially received approximately six hours of training per week, over six months, to become health promotion educators.

Before recruiting for the study, the coworkers engaged in a preintervention process to test the methodology and to increase their skills and confidence. We wanted to ensure that the recruitment, educational module, and materials had face validity in the community and were not unduly influenced by our perspective alone. Development of the format and content of the educational component of the intervention was informed by the Theory of Planned Behavior (Ajzen, 1991; Connor \& Sparks, 1996) and to a lesser extent, the Health Belief Model (Calnan \& Rutter, 1986; Carter, 1990). The advisory group reviewed the field protocol and made recommendations for safety and cultural connectedness that would help field research staff feel comfortable in carrying out the health promotion initiative while not compromising the research agenda.

\section{IMPLEMENTATION}

The SOMW project used social support networks to develop a research infrastructure of women who could extend culturally appropriate social support at multiple levels in their respective communities. Conceptually, the implementation of the health promotion intervention was steeped in community capacity enhancement. Coworkers carried out the intervention, and a community advisory group guided the research in the field. These resources existed in the community before initiation of the SOMW project and needed only to be enhanced to achieve capacity (Saleebey, 2002).

\section{Intervention}

Coworkers facilitated five steps in recruiting women for the study.They (1) explained the SOMW project to the women at the meeting, (2) identified women 30 to 45 years of age and encouraged them to participate, (3) asked each age-eligible woman to think of one or two older women (50 years and older) 
she could encourage to participate in the project, (4) asked the younger woman to get permission from the older woman to enroll her in the study, and (5) followed up with the younger woman one week later to get the name, address, and telephone number of the older woman who would enroll in the SOMW project. The project was approved by the New England Research Institutes' Human Subjects' Review Committee (Institutional Review Board).

At the recommendation of the coworkers, the study was publicized in cohesive group settings such as churches, social clubs, and community organizations; public settings such as beauty salons, libraries, and community social event (cultural festivals); and health care facilities, including health clinic waiting rooms and mobile health vans. Coworkers also arranged face-to-face interactions in the homes of potential participants, in addition to hosting recruitment sessions around town in nonconventional settings, such as supermarkets and train and bus stops. According to Delgado and Humm-Delgado (1982), many of these types of community settings represent a source of strength in ethnic minority communities and should be considered when developing culturally appropriate interventions.

It was important to spread the recruitment sessions around the cities to ensure that African American and Latino neighborhoods were being reached, including low-income housing projects (ShaversHornaday et al.,1997). By taking the research study into the community rather than having the participants come to our research institution, we decreased barriers to participation such as transportation, language differences, and a cultural disconnect.

\section{Younger Women from the Community}

Women between 30 and 45 years of age were asked to nominate an older woman for health promotion. Evidence suggests that most mammography and cervical cancer prevention literature, ad campaigns, and other health promotion devices (Rimer, 1994; Williams, Abbott, \& Taylor, 1997; Yancey \& Walden, 1994) are intended for this age group, and it has been documented (McGadney-Douglass, 2000) that women younger than 50 are more likely to have regular contact with cancer screening services than their older counterparts and feel more comfortable using these services. Moreover, the community capacity-enhancement framework supports the notion of bringing people together across age groups to accomplish goals (Delgado, 2000). These younger women were members of informal support networks that became key to the SOMW health promotion process. We obtained informed consent from the younger and older women in the study. No monetary compensation was provided to respondents, and participation was strictly voluntary and confidential.

\section{Recruitment in the Community}

The recruitment sessions were randomized to intervention or comparison conditions before the scheduling of initial contact with the women in the community. For each recruitment session, the coworker received a sealed recruitment packet, numbered in sequence with a three-digit recruitment session identification number, which allowed us to track the study enrollments. The packets included data collection forms, which were used to gather demographics such as name, age, address, telephone or contact number, language preference, and race or ethnicity. All program materials were available in English and Spanish.

\section{Follow-Ups}

In addition to the one-week call at baseline to identify older women for the study and to review research protocol, a six-week booster call was made to the younger women in the intervention group to further support the health education training that they received. This was meant to enhance the coworker's capacity to promote health behaviors as well.

All of the women enrolled in the study at the end of 12 months participated in a telephone follow-up interview with questions regarding background characteristics, health behaviors and practices, attitudes and intentions, and the effectiveness of younger women to promote health behaviors among older women.

\section{EVALUATION}

Evaluation of the SOMW project included analyses of health behavior outcomes and experiences from the community using survey interviews with the younger and older women (Zapka, ChasanTaber, Bigelow, \& Hurley, 1994) and focus group discussions, field notes, and narratives (McGraw et al., 1996) from community members. We documented the successes and limitations of the health promotion strategy as well as lessons learned. 


\section{Health Behavior Outcomes}

With the necessary health education and skills training, coworkers recruited women from eight different types of locations: (1) out door community events, including community festivals and large health fairs; (2) hair salons; (3) public events held at a community agency building and smaller, targeted health fairs; (4) educational or service-oriented programs; (5) door-to-door recruitment and sessions held in private homes by invitation; (6) churches; (7) health clinic waiting rooms (family health center and mobile health vans; and (8) public areas (parks, public transportation stops, grocery stores, and libraries).

One hundred fifty-one recruitment sessions were held over a $22-$ month period. A total of 549 younger women were willing to encourage an older woman of color to participate in the study, but only half obtained agreement from their nominees. Two-thirds of these women $(n=432)$ fit the age eligibility criteria ( 30 to 45 years) and slightly more than half of them identified an older woman of color to pair with her in the study. Some younger women nominated two older women, yielding 238 younger women who successfully encouraged 281 older women of color to participate in the SOMW project. Fifty-eight percent of the older women nominated by younger women in the comparison group agreed to participate, compared with 48 percent who were randomized to the intervention condition. After six weeks, 75 percent of the intervention group nominators reported talking with the older women about the cancer screening exams.

Of the 238 younger women, 82.8 percent $(n=$ 197) completed the 12 -month interview; 66.9 percent $(n=188)$ of the older women completed the 12 -month follow-up interview. As reported in earlier research (Bullock, Crawford, \& Tennstedt, 2003), we also found that the social support networks of older women, most often, consisted of family members.

\section{Experiences from the Community}

The experiences from the community provide insight into the development of community-based research. Both the coworkers and advisory group were involved in a process evaluation (McGraw et al.,1996), which was conducted through individual and group meetings with community members, as well as through field notes. The viewpoints of these community members provide considerable insight into challenges and opportunities for social workers who undertake health promotion in communities of color.

Community Outreach Workers. Feedback from coworkers indicated that they found the health promotion training informative, stimulating, and useful. Initially those who achieved only a high school education found the theoretical sessions (for example, explanations of "what research is" and "health care barriers and behaviors") difficult. Subsequently, the pace at which the topics were covered was reduced. Later sessions covering problem solving, research skills and practices, in-group exercises, and role-plays were easily negotiated.

The coworkers found recruiting respondents and conducting the research generally interesting, enjoyable, and worthwhile. One woman reported: "I never expected it would be such a challenge to get some of these older women to participate. I think they just didn't trust that the information would not be shared with others. When that happens, I don't enjoy the work as much." As expected (Gamble, 1993), trust in the coworkers and absolute confidentiality were critically important issues for study participants, and coworkers reported that the latter was a reason some women declined to complete the final interview. Although coworkers anticipated and empathized with participants' experiences, they found many accounts to be empowering as they grew concerned about the relative lack of knowledge about cancer and where to go for preventive health care.

Preparing the women to function as coworkers in the health promotion was challenging. Initially, most noticeable was the pace of task completion and expectations for realizing information from the research. A coworker commented:"I think it's more important to build a relationship with the woman than to just rush in and ask the questions and rush out. That's just not my style." The need to moderate the pace of the project became clear to the research team and project manager when they considered the complexities of coming to consensus with coworkers and the research team regarding the goals of the research project and those of the community advisory group. A coworker said, "I don't think most people in my community realize how much we don't know about health and illness, and where to go for services. It's going to take more time than you think." Providing the 
contact list of local resources to respondents was therefore a meaningful strategy in the research process, and the coworkers found it particularly useful in their efforts to promote health behaviors.

Maintaining the research focus and health promotion activities was contingent on the coworkers' capabilities and willingness to perform the tasks. Although coworkers found little difficulty in engaging in discussion with the community advisory group, they were understandably anxious when addressing the SOMW research team. This has been noted in earlier community research initiatives (Swanson \&Ward, 1995). The field notes were helpful in documenting these types of experiences. A coworker said:

\section{"Today I don't feel like going into the commu- nity. I have to sit on the [mobile] van waiting for women to come in for health information. I'm not sure they want this information because some days not a single woman shows up. If they don't come to us, we have to go knocking door- to-door and I'm not sure that will even make a difference. Maybe I won't go out today."}

We were flexible in moving through the various phases of the research (Delgado, 2000) and provided ongoing training and support to coworkers as needed. Sometimes coworkers expressed concern about being adequately prepared to perform certain data collection functions. For example, a coworker expressed discomfort about the sharing of patients'medical records with the research team. Coworkers felt hesitant to discuss various clinical tests and related information in preparing younger women to promote screening exams. When it was explained to the coworkers that this information was a necessary component of the research proto$\mathrm{col}$, some resistance was displayed. Arguably, these tensions helped lead to useful outcomes for health screening decision making within the research time frame and sustaining community involvement.

Training and research were regarded positively in terms of community capacity enhancement and as a personal career development opportunity yielding practical skills and experience. One coworker said, "I am happy to have some job skills that can help me to get another job when this [research] is over."

All of the women who were hired as coworkers on the project have subsequently progressed to continuing employment and regarded the project experience and training as helpful in achieving this. Two of them remained in health promotion settings, another moved to community development, another to advisory posts in both statutory and voluntary sectors, and two others work as data collectors in research environments. This will allow for some level of sustainability in their communities. A coworker said,"I find myself still talking with women in the community about the importance of cancer screening, even though we're finished with the SOMW recruitment."

Community Advisory Group. The community advisory group played a central role in the sustainability of the SOMW project in their community, although an early and continuous challenge for the research team was the differing cultures of community professionals and the research team. A community advisory group member said, "we expect that you will keep us informed and allow us to guide you through our community as you plan this research project. We have people already in our community who could do whatever tasks you need done." The group emphasized the need for careful community enhancement through patience with coworkers' training, research recruitment, and other fieldwork. The research team was accustomed to operating within finite time-scales, particularly those affecting the designation of research timelines and budget constraints. The community advisory group was less concerned with those boundaries.

Confidentiality was of great concern for the advisory group as it was for the coworkers and the research team. An advisory group member who was also a professional at one of the community health care facilities told us: "I don't understand why you have to verify whether the woman actually had the Pap test or not. Why can't you just take her word for it?" Although she failed to understand the distinction between sharing information outside the context of the research protocol and sharing it appropriately to validate the research findings and promote health behaviors, the shared priorities, concerns, and expectations of the community participants were understood and appreciated. The discussions among the community advisory group and the research team left the community members feeling positive that they had contributed to real change in their communities. A group member said: 
"Our community is often the target of research, but we don't often get to be this involved in the process. Now, I feel like we all have a better understanding of what it takes to make a difference in the cancer rates among our women.We just have to make sure we keep this information in our faces, some place where we are likely to see it...like at the train station or the bus station."

\section{Limitations of the Study}

Selection bias was a problem given that the women were identified through informal contacts and largely self-selected to attend the recruitment sessions and to participate in the project. This may have partly affected the rates of preventive health services use because these women were socially active enough to be attending gatherings where they could be recruited. It is possible that women who are socially connected may already have higher rates of preventive health services use.Thus, research should be conducted to look at the extent to which social networks promote positive health outcomes in general. Despite the limitations, the present study provides a guide for practitioners to enhance public health and community outreach. Also, researchers should cross-validate findings with larger samples of racial and ethnic minority women and economically disadvantaged communities.

\section{IMPLICATIONS FOR SOCIAL WORK}

Community development is a basic goal of the social work profession. NASW's Community Development policy statement advocates for helping to find ways to improve individual, social, and physical well-being (National Association of Social Worker, 2000).The SOMW intervention enhanced the capacity of the community by partnering with social workers, medical staff, and community participants. The intervention was premised on the belief that these communities possess the ability and inner resources for capacity enhancement for health promotion (Hurdle, 2001; Morrison et al., 1997; Sullivan et al., 2001).

Conducting the research in communities that had cancer-screening programs was important in eliminating barriers to access among women who desired a cancer-screening exam. Consequently, the study offered the opportunity to examine the effect of the intervention without the confounding influences of access that often pervade these com- munities (Logan \& Freeman, 2000; Ramirez-Valles, 2001). Advocates of health promotion in communities of color must consider approaches that enhance the capacity of the residents to make the necessary changes and provide a framework for effective collaboration (Cardin et al.,2001; Morrison et al., 1997).

\section{Lessons Learned}

Health intervention practices can thrive in a setting with a supportive infrastructure and well-organized social services networks. The community capacity-enhancement framework suggests that when feasible, community projects should bring people together across age groups to accomplish goals (Poole, 1997).Yet, there is little guidance within the professional literature about how to conduct such research. The paucity of guidelines for social workers to undertake culturally specific community health promotion necessitates research demonstration projects like SOMW.

This research confirmed that women of color could be hired and trained to function as community outreach workers and to recruit participants from their community as a health intervention strategy. There was a sense of ownership among the coworkers that was inspiring. Consider what one woman said: "Though the research team is fine to work with and seem to connect with us, the people in the community really see this as our project and see us as the ones who are trying to help them and that's what will make this a success."The community capacity-enhancement approach provided opportunities to not only reach older women of color who typically underuse preventive health services like cancer screening, but also to create a sense of responsibility for health practices and maintenance within their community.

To effectively gain entry into communities of color, we recommend that social workers enlist the support of community leaders (Braithwaite \& Lythcott, 1989) and lay people in the community (Eng, Parker, \& Harlan, 1997). The critical elements of the SOMW intervention were participation and collaboration between the research team and the community. The sustainability of the SOMW project in the community was greatly facilitated by the pre-existing relationship between the community and the research team. For example, several members of the research team had conducted research in those communities and worked with 
community professionals of the advisory group. This reassured the community representatives that there was a continued interest in improving conditions of their communities.

Ongoing communication with the community representatives was valuable to the research. Discussions, joint planning, and coordination aided our efforts. The quarterly site visits by the research team were critical to the community agencies and the coworkers.Various health care practices were often the focus of these meaningful exchanges. There was a reciprocal sharing of knowledge that informed the research. In particular, behaviors such as allowing the older woman to discuss her participation in the educational intervention with extended family members or friends and permitting the older woman to be accompanied by a friend or family member when being screened by health care providers were emphasized. These behaviors were identified as culturally specific practices among women of color and important in sustaining their trust in the research process.

Effectiveness of the community capacity-enhancement approach was demonstrated in ability of the coworkers to feel a sense of ownership in facilitating health promotion among their community members, who are typically viewed as at risk of health disparities (Braithwaite \& Lythcott, 1989; Logan \& Freeman, 2000). Although the primary objective of this intervention was to increase screening among older women, a secondary benefit was the enhanced attitudes and beliefs regarding the cancer screening exams among the younger women (Ajzen, 1991; Eisner, Zook, Goodman, \& Macario, 2002). Many older women of color in the study were positively influenced by the younger women's encouragement to have the screening exams and reported that they intend to continue receiving the cancer prevention services in the future.

\section{CONCLUSION}

Researchers and practitioners can use the following guidelines in planning and implementing community health promotion intervention with women of color:

- Develop and implement collaborative goals.

- Create a participatory exchange of resources to support the goals.

- Systematically incorporate intergenerational activities into the intervention.
- Help community participants develop skills that create sustainability when possible.

These guidelines require social workers to rely on culturally specific assessment, engagement, implementation, and evaluation processes (Delgado, 2000).

Communities of color are resourceful and may share priorities, concerns, and expectations of researchers and practitioners who target this population. For professionals who intend to conduct health promotion research with older women of color, the SOMW project offers insightful information for planning and evaluating. Such information should also prove useful to foundations that support community initiatives targeted at underserved populations. SOMW is a model for enhancing community resources to achieve health promotion with groups that might otherwise be "hard to reach." HSW

\section{REFERENCES}

Adams, D. L. (1995). Health issues for women of color: A cultural diversity perspective. Thousand Oaks, CA: Sage Publications.

Ajzen, I. (1991). The theory of planned behavior. Organizational Behavior and Human Decision Processes, $50,179-211$.

Allen, M. (1994). The dilemma for women of color in clinical trails. Journal of the American Medicine Women's Association, 49, 105-109.

Altpeter, M., Earp, J. L., \& Schopler, J. H. (1998). Promoting breast cancer screening in rural, African American communities: The "science and art" of community health promotion. Health \& Social Work, $23,104-115$.

American Cancer Society. (2001). Cancer facts \& figures for African Americans. Retrieved on July 24, 2003, from: http://www.3cancer.org/eprise/main/docroot/ STT_1x_2000_Facts_Figures_for_African_Americans

Black, M.E.A., Stein, K. F., \& Loveland-Cherry, C. J. (2001). Older women and mammography screening behavior: Do possible selves contribute? Health Education E Behavior, 28(2), 200-216.

Braithwaite, R. L., \& Lythcott, N. (1989). Community empowerment as a strategy for health promotion for black and other minority populations. JAMA, 261, 282-283.

Bullock, K. (2004). Family social support. In P. J. Bomar (3rd ed.), Nurses and family health promotion: Applying family research and theory in nursing practice (pp. 142161). Philadelphia: W. B. Saunders.

Bullock, K., Crawford, S. L., \& Tennstedt, S. L. (2003). Employment and caregiving: Exploration of African American caregivers. Social Work, 48, 150-162.

Calnan, M., \& Rutter, D. R. (1986). Do health beliefs predict health behavior? An analysis of breast selfexamination. Social Science \& Medicine, 22, 673-678.

Cardin,V.A., Grimes, R. M., Jiang, Z. D., Harrell, L., \& Cano, P. (2001). Low-income minority women at risk for cervical cancer: A process to improve adherence to follow-up recommendations. Public Health Reports, 116, 608-616. 
Carter,W. B. (1990). Health behavior as a rational process: Theory of reasoned action and Multiattribute Utility Theory. In K. Glanz, F. M. Lewis, \& B. K. Rimer (Eds.), Health behavior and health education (pp. 63-91). San Francisco: Jossey-Bass.

Chaskin, R. J., Joseph, M. L. \& Chipenda-Dansokho, S. (1997). Implementing comprehensive community development: Possibilities and limitations. Social Work, 42, 435-444.

Clayton, L. A., \& Byrd, W. M. (1993). The African American cancer crisis, part I: The problem. Journal of Health Care for the Poor and Underserved, 4(2), 83-101.

Connor, M., \& Sparks, P. (1996). The theory of planned behavior and health behaviors. In M. Connor \& $\mathrm{P}$. Norman (Eds.), Predicting health behavior (pp. 121162). Bristol, PA: Open University Press.

Delgado, M. (2000). Community social work practice in an urban context: The potential of a capacity-enhancement practice. New York: Oxford University Press.

Delgado, M., \& Humm-Delgado, D. (1982). Natural support systems: Source of strength in Hispanic communities. Social Work, 27, 83-89.

Eisner, E. J., Zook, E. G., Goodman, N., \& Macario, E. (2002). Knowledge, attitudes, and behavior of women ages 65 and older on mammography screening and Medicare: Results of a national survey. Women \& Health, 36(4), 1-18.

Eng, E., Parker, E., \& Harlan, C. (1997). Lay health advisor intervention strategies: A continuum from natural helping to paraprofessional helping. Health Education \& Behavior, 24, 413-417.

Gamble,V. N. (1993). A legacy of distrust: African Americans and medical research. American Journal of Preventive Medicine, 9, 35-38.

Han, B., Wells, B. L., \& Primas, M. (2003). Comparison of mammography use by older black and white women. Journal of the American Geriatric Society, 51 , 203-212

Hurdle, D. E. (2001). Social support: A critical factor in women's health and health promotion. Health $\&$ Social Work, 26, 72-79.

Lerman, C., Rimer, B. K., Daly, M., Lustbader, E., Sands, C., Balshem, A., Masny, A., \& Engstrom, P. (1994). Recruiting high risk women into a breast cancer health promotion trial. Cancer Epidemiology Biomarkers \& Prevention, 3(3), 271-276.

Lesser, J. G. (2000). Clinical social work and family medicine: A partnership in community service. Health \& Social Work, 25, 119-126.

Levkoff, S., \& Sanchez, H. (2003). Lessons learned about minority recruitment and retention from the Centers on Minority Aging and Health Promotion. Gerontologist, 43, 18-26.

Levy, D. R. (1985). White doctors and black patients: Influence of race on the doctor-patient relationship. Pediatrics, 75, 639-643.

Logan, S. L., \& Freeman, E. M. (2000). Health care in the black community: Empowerment, knowledge, skills, and collectivism. New York: Haworth Press.

Marbella, A. M., \& Layde, P. M. (2001). Racial trends in age-specific breast cancer mortality rates in U.S. women. American Journal of Public Health, 91, 118-121.

Markides, K. S., Rudkin, L., Angel, R. J., \& Espino, D.V. (1997). Health status of Hispanic elderly. In L. G. Martin \& B. J. Soldo (Eds.), Racial and ethnic differences in the health of older Americans (pp. 285300). Washington, DC: National Academies Press.

McGadney-Douglass, B. F. (2000). The health care needs of the black elderly: From well to frail. In S. L. Logan \& E. M. Freeman (Eds.), Health care in the black community: Empowerment, knowledge, skills, and collectivism (pp 115-133). New York: Haworth Press.
McGraw, S. A., Sellers, D. E., Stone, E. J., Bebchuk, J., Edmundson, E. W., Johnson, C. C., Bachman, K. J., \& Luepker, R.V. (1996). Using process data to explain outcomes: An illustration from the Child and Adolescent Trail for Cardiovascular Health (CATCH). Evaluation Review, 20, 291-312.

Morrison, J. D., Howard, J., Johnson, C., Navarro, F. J., Plachetka, B., \& Bell, T. (1997). Strengthening neighborhoods by developing community networks. Social Work, 42, 527-534.

National Association of Social Workers. (2000). Community development. In Social work speaks (5th ed., pp. 45-49). Washington, DC: NASW Press.

National Center for Health Statistics. (2001). U.S. mortality rates by states: 1969-2001. Retrieved June 30, 2001, from http://www.canques.seer.cancer.gov/

Poole, D. L. (1997). Building community capacity to promote social and public health: Challenges for universities. Health $\mathcal{E}$ Social Work, 22, 163-170.

Ramirez, A. G., Talavera, G. A.,Villarreal, R., Suarez, L., McAlister, A., Trapido, E., Pérez-Stable, E., \& Marti, J. (2000). Breast cancer screening in regional Hispanic populations. Health Education Research, 15, 559-568.

Ramirez-Valles, J. (2001). "I was not invited to be a [CHW]...I asked to be one": Motives for community mobilization among women community health workers in Mexico. Health Education \& Behavior, 28, $150-165$.

Ries, L. G., Hankey, B. F., \& Edwards, B. K. (1990). Cancer statistics review 1973-1998. Bethesda, MD: National Cancer Institute.

Rimer, B. K. (1994). Interventions to increase breast screening. Cancer Supplement, 74, 323-328.

Saleebey, D. (2002). Introduction: Power in the people. In D. Saleebey (Ed.), The strengths perspective in social work practice (3rd ed., pp. 1-21). White Plains, NY: Longman.

Sellers, D. E., Crawford, S. L., Bullock, K., \& McKinlay, J. B. (1997). Understanding the variability in the effectiveness of community heart health programs: A meta-analysis. Social Science \& Medicine, 44, 13251339.

Selvin, E., \& Brett, K. M. (2003). Breast and cervical cancer screening: Sociodemographic predictors among white, black, and Hispanic women. American Journal of Public Health, 93, 618-623.

Shavers-Hornaday, V. L., Lynch, C. F. Burmeister, L. F., \& Torner, J. C. (1997). Why are African Americans under-represented in medical research studies: Impediments to participation? Ethnicity and Health, $2(1 / 2), 31-45$.

Skinner, C. S., Arfken, C. L., \& Waterman, B. (2000). Outcomes of the Learn, Share, \& Live breast cancer education program for older urban women. American Journal of Public Health, 90, 1229-1234.

Suarez, L. (1994). Pap smear and mammogram screening in Mexican-American women: The effects of acculturation. American Journal of Public Health, 84, 742-746.

Sullivan, M., Kone, A., Senturia, K. D., Chrisman, N. J., Ciske, S. J., \& Krieger, J. M. (2001). Research and researched-community perspective: Toward bridging the gap. Health Education \& Behavior, 28, 130-149.

Swanson, G., \& Ward, A. (1995). Recruiting minorities into clinical trials: Toward a participant-friendly system. Journal of National Cancer Institute, 87, 17471759.

Tessaro, I., Eng, E., \& Smith, J. (1993). Breast cancer screening in older African American women: Qualitative research findings. American Journal of Health Promotion, 8(4), 286-293. 
U.S. Department of Health and Human Services. (2000). Healthy People 2010. Washington, DC: Author.

Williams, G. A., Abbott, R. R., \& Taylor, D. K. (1997). Using focus group methodology to develop breast cancer screening programs that recruit African American women. Journal of Community Health, 22, 45-56.

Yancey, A., \& Walden, L. (1994). Stimulating cancer screening among Latinas and African American women. Journal of Cancer Education, 9, 46-52.

Zambrana, R. E., \& Ellis, B. K. (1995). Contemporary research issues in Hispanic/Latino women's health. In D. L. Adams (Ed.), Health issues for women of color: $A$ cultural diversity perspective (pp. 42-70). Thousand Oaks, CA: Sage Publications.

Zapka, J. G., Chasan-Taber, L., Bigelow, C., \& Hurley, T. (1994). Methodological issues for health-related surveys of multicultural older women. Evaluation $\mathcal{E}$ The Health Professions, 17, 485-500.

Karen Bullock, PhD, is assistant professor, School of Social Work, University of Connecticut, 1798 Asylum Avenue, West Hartford, CT 06117, and research scientist at the Braceland Center for Mental Health and Aging at Hartford Hospital,Hartford, CT; e-mail: karen.bullock@uconn.edu. Sarah A. McGraw, PhD, is senior research scientist, New England Research Institutes, Watertown, MA. This research was supported by grant R01 CA73496 from the National Cancer Institute.

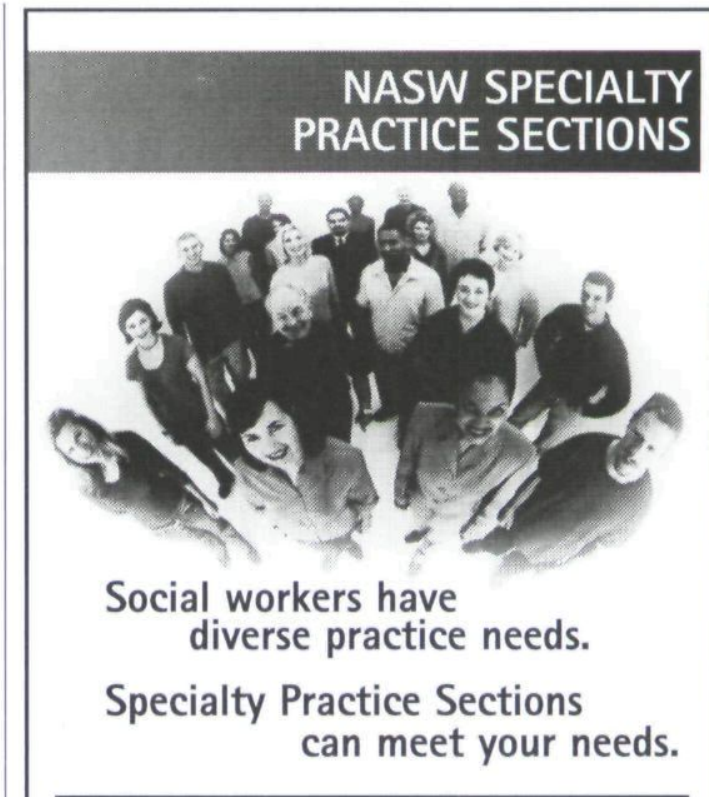

NASW's Specialty

NASW SPECIALTY

Practice Sections link you PRACTICE SECTIONS

with the key information, - Aging

resources, and expertise

you need to stay at the

forefront of your practice

specialty and advance in

your career-

- Customized services

- Practice-specific newsletters, updates, and advocacy alerts

- Members-only Web page

- Networking with colleagues

- Professional advancement opportunities, and more

- Alcohol, Tobacco, and Other Drugs (ATOD)

- Child Welfare

- Health

- Mental Health

- Poverty and Social Justice

- Private Practice

- School Social Work

-You must be a current NASW member to join a Specialty Practice Section. For more information on NASW membership and benefits, go to www.socialworkers.org or call 800-638-8799.

\section{Join more than one!*}

www.socialworkers.org/sections 202-408-8600 ext. 499

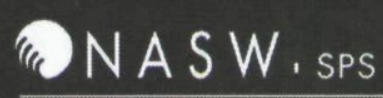

National Association of Social Workers Spetriaty Practice Sections 
Copyright of Health \& Social Work is the property of National Association of Social Workers and its content may not be copied or emailed to multiple sites or posted to a listserv without the copyright holder's express written permission. However, users may print, download, or email articles for individual use. 